\title{
Application of surface-active substances produced by Nocardia vaccinii IMB B-7405 for the treatment of vegetables
}

\section{Tetiana Pirog ${ }^{1,2}$, Kristina Beregova ${ }^{1}$, Bogdana Geichenko, Viktor Stabnikov ${ }^{1}$}

\author{
1 - National University of Food Technologies, Kyiv, Ukraine \\ 2 - Institute of Microbiology and Virology NAS of Ukraine, Kyiv, Ukraine
}

Keywords:

Vegetables

Biosurfactant

Nocardia vaccinii IMV

B-7405

Shelf life

Article history:

Received 24.09.2018

Received in revised form

27.12.2018

Accepted 28.03.2019

Corresponding author:

Viktor Stabnikov

E-mail:

vstabnikov1@gmail.com

DOI: $10.24263 / 2304-$

974X-2019-8-1-11

\section{Abstract}

Introduction. Application of surface-active substances (SAS) produced by Nocardia vaccinii IMV B7405 for shelf live extension of vegetables was studied.

Materials and methods. Organic vegetables such as tomato, cucumbers, and squashes were washed with the solution of SAS produced by $N$. vaccinii IMV B-7405 with concentrations of 0.25 or $0.5 \mathrm{~g} / \mathrm{L}$. Microbiological analysis was done before the beginning of the vegetables storage. Evaluation of vegetable quality was conducted by viewing during time of the storage.

Results and discussion. The results of our research showed the efficiency of the application of biosurfactant produced by Nocardia vaccinii IMV B-7405 using industrial wastes for shelf life extension of vegetables. Results of visible observations as well as microbiological analysis showed that the treatment of vegetables with SAS solutions at the concentrations of 0.25 and $0.5 \mathrm{~g} / \mathrm{L}$ was more effective than washing them with tap water. The total number of heterotrophic bacteria and fungi in the samples decreased after treatment of vegetables with SAS of $N$. vaccinii IMV B-7405 by 16-34 and 3-14 times, respectively, meanwhile the washing of vegetables with tap water decreased total microbial number only by $2-2.5$ times. It was shown that vegetables washed with water spoiled faster than those treated with SAS solution. The advantages of application of this biosurfactant for vegetables post-harvest treatment are that (1) it can be used at the lower by 2-6 times concentration in comparison with other reported in literature microbial SAS, and (2) it can be produced using industrial wastes that will reduce the cost of its production.

Conclusion. Biosurfactant produced by Nocardia vaccinii IMV B-7405 can be used for the treatment of vegetables to extent their shelf life. 


\section{Introduction}

Shelf life of fresh vegetables is a matter of great importance. According to statistics of the Food and Agriculture Organization of the United Nations (FAOSTAT), the developed countries lose only $5 \%$ of the harvest due to the more perfect technologies of vegetables storage, meanwhile in the other countries the losses of harvest can be above $20 \%[1,2]$. For example, in China the losses of 30 million tons of annual garden-stuffs economic damages can be estimated as 30 billion yuan [1-3]. Ukraine is one of the leading world producers of vegetables. However, the total post-harvest losses were assessed as 800-964 thousand tons in 2017 [4], which consist about US\$30-37 million. To extend shelf life of vegetables they can be treated using physical methods such as hot-water immersion, low temperature storage, modified atmosphere packaging technology, the treatment with gamma radiation or by pulsed electric field and chemical methods such as application of acidifying agents, chemical reductants, inhibitors of enzymes activities, sequestrants [5-8]. The treatment of the vegetables using physical methods can cause their mechanical damages such as bruises, abrasions and cuts which make them more sensitive to desiccation and shriveling, increase in respiration rate and ethylene emission, speed up the wilting and enzymatic browning. The high temperatures can cause yellow discoloration of green vegetables, and the use of modified atmosphere packing stipulates determination of optimal gas composition for every certain product [8]. Application of the physical methods for vegetables treatment also requires special equipment.

Application of synthetic chemical substances for surface treatment of vegetables is not appreciated by consumers because of the health concerns. For example, application of such widely used as a post-harvest dip of crops synthetic antioxidants as ethoxyquin and diphenylamine are under regulatory restrictions [7]. So, the global trend is to decrease the use of the synthetic chemical substance for prolongation of the vegetables shell life. To do it, the development of alternative safe methods is needed. The antimicrobial and antiadhesion efficiency of nontoxic biodegradable microbial surface-active substances (SAS), for example, sophrolipids and rhamnolipids, to treat the agricultural products was shown [9-13]. However, this treatment is costly. To diminish the cost of the post-harvest treatment of vegetables with microbial polysaccharides the strain producing surface active substances that are by one order of magnitude more active than known substances was selected and studied. The strain of hydrocarbon-oxidizing bacteria Nocardia vaccinii IMV B-7405 isolated from the oil-polluted soil was able to synthesize substances, which had surface activity and emulsion properties [13]. It was shown that this biosurfactants had also antimicrobial and antiadhesive properties $[14,15]$ and was active against phytopathogenic bacteria of the geniuses Pseudomonas and Xanthomonas [16].

The aim of the present research was testing of the surface active substances produced by $N$. vaccinii IMV B-7405 for the vegetables treatment to extent their shelf life.

\section{Materials and methods}

\section{Microorganism}

The strain Nocardia vaccinii IMV B-7405 was isolated from the oil-polluted soil [13] and was deposited in the Collection of Microorganisms of Institute of Microbiology and Virology NAS of Ukraine. The biosurfactant produced by $N$. vaccinii IMV B-7405 was a set of neutral, glyco- and aminolipids. Neutral lipids contained mycolic and n-alkanoic acids, glycolipids contained trehalose diacelates and trehalose mycolates [14]. 


\section{Cultivation of $N$. vaccinii IMV B-7405}

Bacterial strain $N$. vaccinii IMV B-7405 was cultivated in the liquid mineral medium with the following composition, g/L: $\mathrm{NaNO}_{3}, 0.5 ; \mathrm{MgSO}_{4} \cdot 7 \mathrm{H}_{2} \mathrm{O}, 0.1 ; \mathrm{CaCl} \cdot 2 \mathrm{H}_{2} \mathrm{O}, 0.1$; $\mathrm{KH}_{2} \mathrm{PO}_{4}, 0.1 ; \mathrm{FeSO}_{4} \cdot 7 \mathrm{H}_{2} \mathrm{O}, 0.001$, yeasts extract, 0.5 vol\%, distilled water $1 \mathrm{~L}$. Crude glycerol which is waste from biodiesel production plant, Poltava region, Ukraine, was used as a source of carbon in the concentration of $2 \mathrm{vol} . \%$. Inoculum was prepared by cultivation of the strain N. vaccinii IMB B-7405 in the medium described above with 0.5 vol.\%. of crude glycerol. The cultural liquid with the concentration of bacterial cells $10^{4}-10^{5}$ cells $/ \mathrm{mL}$ was taken from the exponential growth phase and was added to the medium for the strain cultivation, 10 vol.\%. Cultivation of $N$. vaccinii IMV B-7405 was conducted in the flasks with the volume of $750 \mathrm{~mL}$ in $100 \mathrm{~mL}$ of medium under shaking at $320 \mathrm{rpm}$ at $30^{\circ} \mathrm{C}$ during 120 hours.

\section{Production of surface-active substances}

The cultural liquid after cultivation was centrifuged at $5000 \times \mathrm{g}$ for 45 minutes (laboratory centrifuge LP-8, Kiev, Ukraine). The Folch solution (chloroform and methanol in volume ratio 2:1) was used for extraction of surface-active substances. The supernatant was placed in the funnel, then Folch solution was added (ratio 1:1), and the mixture was shaken for $5 \mathrm{~min}$ and left for phase separation. The lower fraction (organic extract 1) was removed, and the extraction procedure was repeated twice to obtain organic extracts 2 and 3 . All extracts were combined and evaporated on the rotor evaporator ER-1M2 (Russia) at the temperature $50{ }^{\circ} \mathrm{C}$ and pressure $0.4 \mathrm{~atm}$ to the constant weight. The dry SAS was dissolved in water and solution of biosurfactant with its concentration of $0.25-0.5 \mathrm{~g} / \mathrm{L}$ was used in the research.

\section{Vegetables}

Organic vegetables such as tomato red (Admiral variety) and green (Malachite casket variety), cucumbers (Conni F1 variety), squashes (Airoil variety) were grown in the open ground without treatment with pesticides in Gvozdev, Kyiv Oblast, Ukraine, GPS $\left.50^{\circ} 14^{\prime} 53.5^{\prime \prime} \mathrm{N} 30^{\circ} 28^{\prime} 41.3^{\prime \prime} \mathrm{E}\right)$. The harvested vegetables were ripe, without visible damages and infections

\section{Vegetable washing}

To study the influence of the vegetable treatment with SAS of $N$. vaccinii IMV B-7405 on the storage duration, picked up vegetables were divided into three groups with $10-30$ pieces in each. Vegetables of the first group were not treated at all, vegetables of the second group were washed with tap water, and vegetables of the third group were washed with the solutions of SAS with concentrations of 0.25 or $0.5 \mathrm{~g} / \mathrm{L}$. Vegetables were placed in the glass cylinder, $250 \mathrm{~mL}$ of tap water or the SAS solution was added, treatment lasted for $5 \mathrm{~min}$, and after that vegetables were taken off and placed on the plates at the room temperature for observation [8]. Microbiological analysis was done before the beginning of the vegetables storage. 


\section{Microbiological analysis}

Some vegetables from each group were taken with sterile pincers, then they were placed into sterile porcelain jar and were pestling. Homogenized mixture, $10 \mathrm{~g}$, were placed into flask with $90 \mathrm{~mL}$ of sterile tap water and shaken. The quantity of microbial cells (colonyforming units, CFU) was determined by the plate diluting method. The quantity of heterotrophic bacteria was determined by their growth on the beef-extract agar-agar (BEAA) at $37^{\circ} \mathrm{C}$ for 24 hours, and the quantity of the fungi was determined by their growth on the Wort Agar for microbiology at $30^{\circ} \mathrm{C}$ for 48 hours.

\section{Evaluation of vegetable quality}

Evaluation of vegetable quality was conducted by viewing during time of the storage. The experiment was finished when the signs of deterioration (usually on the seventh day) such as decay, changes of color and texture, the presence of the cracks and wrinkling were evident on all vegetables.

\section{Statistical analysis}

All experiments were done in triplicates, the number of the parallel determinations varied from 3 to 5. Statistical analysis was done using computer program Statistix 10.0 for Windows version 11.5. The average means $(\mathrm{M})$ and standard deviations (SD) were calculated for the experimental results.

\section{Results and discussion}

From the different vegetables, which are cultivated in Ukraine, the cucumbers, the squashes, and the tomatoes were chosen for our experiments by the following reasons: (1) according to the data of FAOSTAT Ukraine occupies sixth place in the world on the cucumbers production going ahead USA and Spain and is within the top twenty exporting countries [17]; Ukraine is a leader in Europe in the production of tomatoes, and the part of tomato's production contributes $20 \%$. of overall fruit-and-vegetable production of the country [18]. In addition, tomatoes unlike vegetable marrows and cucumbers belong to the soft garden-stuffs, so at the longtime transportation or storage they are quickly infected by microorganisms and spoiled.

In the studies of the influence of microbial SAS on the extension of the storage time of fruit-and-vegetables products high enough concentration of preparations, $1-3 \mathrm{~g} / \mathrm{L}$, were used [2, 8, 18-21]. Our previous studies showed that SAS synthesized by N.vaccinii IMV B7405 had high antimicrobial activities [16]: the minimum inhibiting concentration (MIC) against phytopathogenic bacteria Pectobacterium carotovorum UKM B-1095, Pseudomonas syringae pv. atrofaciens UKM B-1015 and Xanthomonas campestris pv. campestris UKM B-1049 were 14-52 $\mu \mathrm{g} / \mathrm{mL}$, meanwhile MIC of SAS reported in the literature were higher. So, MIC of SAS synthetized by Candida bombicola ATCC 22214 against 18 phytopathogenic fungi (Alternaria tomatophilia, Alternaria solani, Alternaria alternata, Aspergillus niger, Aureobasidium pullulans, Bacillus cinerea, Chaetomium globosum, Fusarium asiaticum, Fusarium austroamericana, Fusarium cerealis, Fusarium graminearum, Fusarium oxysporum, Penicillium chrysogenum, Penicillium digitatum, Penicillium funiculosum, Phytophtera infestans, Phytopthora capsici, Ustilago maydis) and 7 phytopathogenic bacteria (Acidovorax carotovorum, Erwinia amylovora, Pseudomonas 
cichorii, Pseudomonas syringae, Pectobacterium carotovorum, Ralstonia solanacearum, Xanthomonas campestris) was in the range $2.5-10 \mathrm{mg} / \mathrm{mL}$ [23]. Therefore, in our present study the lower concentration of SAS produced by N.vaccinii IMV B-7405 $(0.25-0.5 \mathrm{~g} / \mathrm{L})$ and used in experiments was comparable with the concentrations reported in the literature (1$3 \mathrm{~g} / \mathrm{L})$.

Visual supervision of the cucumbers and the squashes shown that the samples treated with SAS did not have the signs of spoilage after 7 days of storage in comparison with ones washed with water (Figure 1).

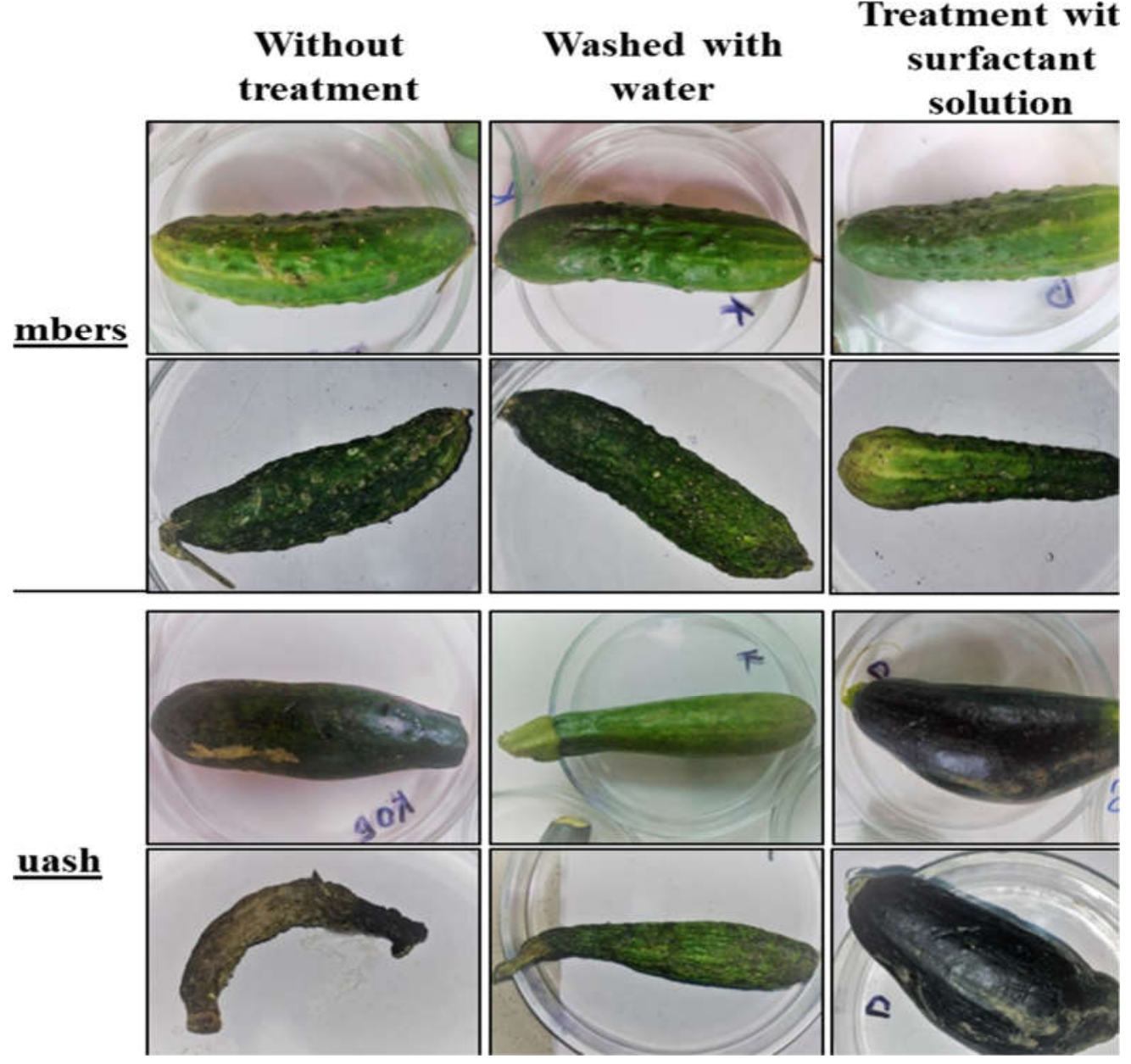

Figure 1. Effect of the treatment of the cucumbers and squashes with SAS produced by N. vaccinii IMV B-7405 (0.5 g/L) on their storage.

The spoilage of the non-treated and washed with water tomatoes was observed on the third day of their storage; meanwhile tomatoes treated with SAS did not show the signs of spoilage even on the seventh day (Figure 2). 


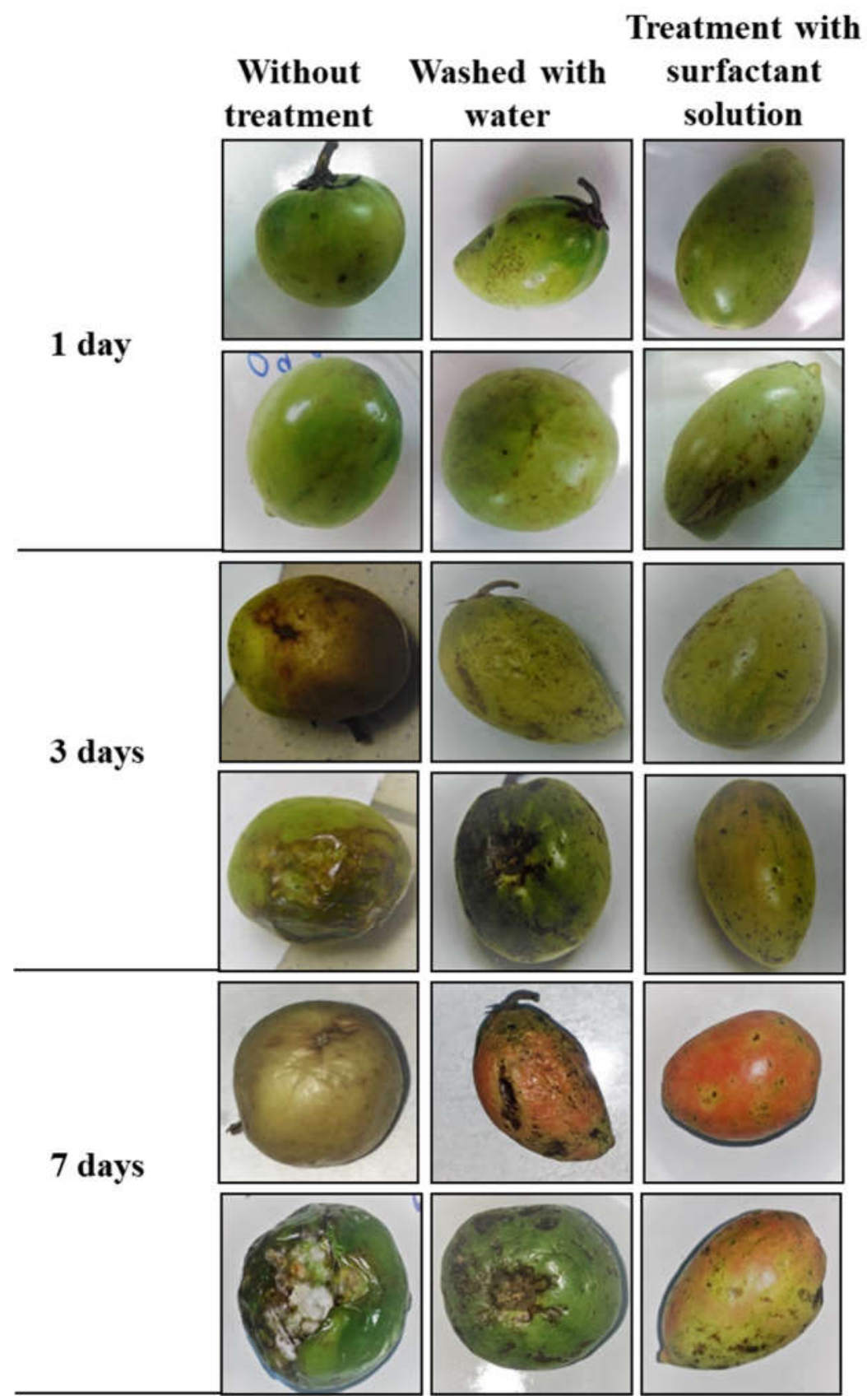

Figure 2. Effect of the treatment of green tomatoes with SAS produced by N. vaccinii IMV B-7405 (0.5 g/L) on their storage. 
The results of microbiological analysis of the surface of the green tomatoes without any treatment, after washing with water and after the treatment with SAS are shown in the Figure 3.
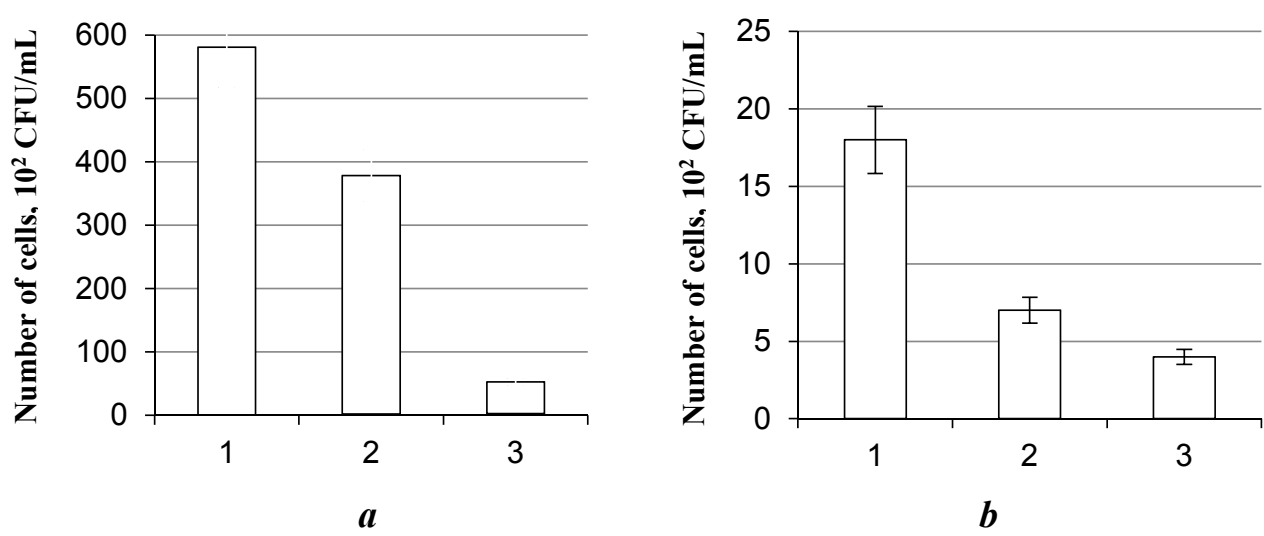

Figure 3. Total number of heterotrophic bacteria (A) and fungi (B) on the surface of green tomatoes depending on the method of their treatment:

1 - without treatment; 2 - treatment with water;

3 - treatment with surfactant solutions, $0.5 \mathrm{~g} / \mathrm{L}$.

It was shown that after washing the quantity of the bacterial and fungi cells on the surface of green tomatoes was diminished by 1.6 and 2.4 times, meanwhile after treatment with the SAS solution it was diminished by 10.8 and 2.8 times, respectively, in comparison with the non-treated green tomatoes (Figure 3, A,B).

Red tomatoes were treated with the solutions of SAS of $0.5 \%$ and $0.25 \%$. It was shown, that in the case when the treatment of the red tomatoes was done with the solutions of SAS at the concentrations of 0.25 or $0.5 \mathrm{~g} / \mathrm{L}$ the quantity of bacterial cells diminished by 6 and 14 times, and the concentrations of fungi diminished by 1.5 and 7 timed, respectively, in comparison with the tomatoes washed with water (Figure 4, A, B).

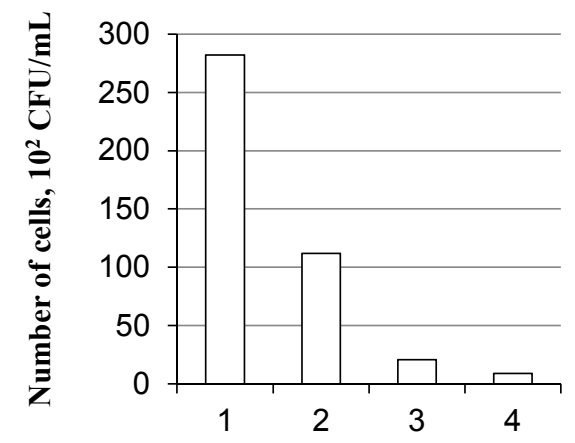

$a$

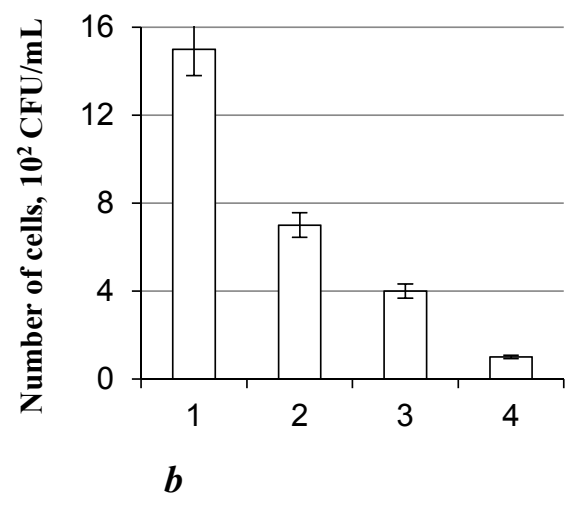

$b$

Figure 4. Total number of heterotrophic bacteria (A) and fungi (B) on the surface of red tomatoes depending on the method of their treatment: 1 , without treatment; 2 , treatment with water; 3 , treatment with surfactant solutions, $0.25 \mathrm{~g} / \mathrm{L} ; 4$, treatment with surfactant solutions, $0.5 \mathrm{~g} / \mathrm{L}$. 
According to the visual observation, external appearance of tomatoes treated with the SAS solutions with concentration 0.25 or $0.5 \%$ on the seventh day was almost the same (Figure 5). Taking into account the economic consideration, dosage of SAS $0.25 \mathrm{~g} / \mathrm{L}$ was recommended for the treatment of vegetables for extension of their shelf life, notwithstanding that concentration of SAS $0.5 \mathrm{~g} / \mathrm{L}$ was more effective.

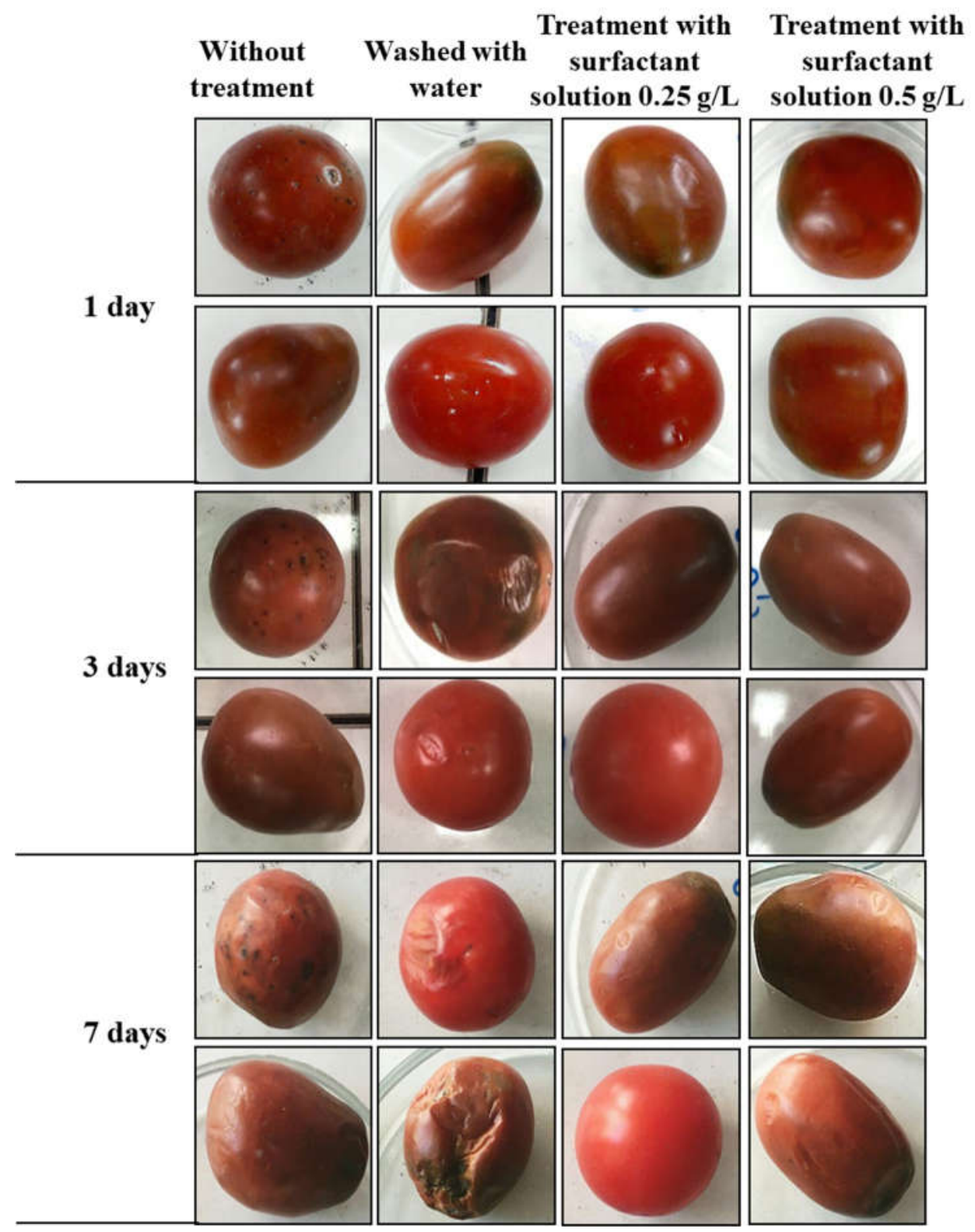

Figure 5. Effect of the treatment of the red tomatoes with different concentrations of SAS produced by $N$. vaccinii IMV B-7405 on their storage 
Currently, there are known only some studies of applications of microbial surfactants for fruit and vegetables treatment, and the industrial production of these surfactants (rhamnoand sophorolipids) is conducted by only few companies, the most of which work in the USA [24]. American companies AGAE Technologies LLC, Jeneil Biosurfactant Co. LLC, Paradigm Biomedical Inc., Rhamnolipid Companies Inc. produce rhamnolipids to be used in pharmaceuticals industry, agriculture, for bioremediation of polluted environment, and to increase of oil production. Japanese companies Saraya Co. Ltd. and Allied Carbon Solutions (ACS) LTD Japan produce sophorolipids, which are used in the manufacturing of cleaning and hygiene products, as well as in agriculture.

Low yield of biosynthesized SAS and their high production cost are the major restrictions for their wide use. One of the ways to diminish the cost of biosurfactant production is the use of the waste materials as substrates for SAS biosynthesis [25], for example, wastes from fat-and-oil, sugar, and milk industries, agriculture and forestry, production of biodiesel, and used (overdone) oils. The most suitable substances for the biosynthesis of the microbial surfactants are oil-containing wastes, which unlike lignin- and cellulose-containing wastes, milk whey, and technical glycerin, do not need preliminary treatment and purification.

It was shown in our previous studies that the wastes from the biodiesel production and used sunflower oil can serve as the substrates for cultivation of N.vaccinii IMB B-7405 and synthesis of biosurfactant $[14,26]$. Additionally, this biosurfactant can be used for the vegetables treatment in the concentrations much lower than ones that are reported in the literature. So, sophorolipids produced by Wickerhamiella domercqiae Y2a CGMCC3798 were used to treat citruses, peaches and apricots in the concentrations of $1-3 \mathrm{~g} / \mathrm{L}$ [2]. It was shown that the strongest hyphae growth spread of Aspergillus niger, Aspergillus flavus and Penicillium (agent of fruits putrefaction) was suppressed at concentration of the sophorolipids fruit preservative of $3 \mathrm{~g} / \mathrm{L}$ [2]. Inhibiting effect of the treatment of Eugenia uniflora (Surinam cherry, pitanga) with rhamnolipids solution produced by Pseudomonas aeruginosa LBI in the concentration of $1 \mathrm{~g} / \mathrm{L}$ was shown [7]. It is known that biosurfactants can be used at the lower concentrations but only in combination with other components, for example, with synthetic SAS or with microorganisms, which are antagonists of phytopathogens. So, Yan with coauthors showed the synergetic effect of rhamnolipids of Pseudomonas aeruginosa $(0.5 \mathrm{~g} / \mathrm{L})$ and suspension of the yeasts Rhodotorula glutinis $\left(1 \times 10^{8}\right.$ cells $/ \mathrm{mL}$ ) in suppressing Alternaria alternata on cherry tomato [19]. A simultaneous application of $R$. glutinis and rhamnolipids to treat the tomato surface to control post-harvest diseases was more effective than application of yeasts and biosurfactants alone. Application of $0.25 \%$ solution of sophorolipids, synthesized by Candida bombicola ATCC 22214, in combination with synthetic SAS polyethylene glycol was effective against Erwinia chrysanthemi ATCC 11663 and Xanthomonas campestris ATCC 13951 on the surface of chikoos, tomatoes, cucumbers, and citruses [22].

\section{Conclusions}

The results of our research showed the efficiency of the application of biosurfactant produced by Nocardia vaccinii IMV B-7405 for shelf life extension of vegetables. The advantages of application of this biosurfactant for vegetables post-harvest treatment are that (1) it can be used at the lower by 2-6 times concentration in comparison with other reported in literature microbial SAS, and (2) it can be produced using industrial wastes that will reduce the cost of its production. 
So, use of biosurfactant synthesized by N.vaccinii IMB B-7405, which will be produced using industrial wastes, can resolve such important problems as utilization of the toxic industrial wastes, decrease of the cost of biodiesel production, and extend the shelf life of vegetables during their storage and transportation.

\section{References}

1. Kader A.A. (2005), Increasing food availability by reducing postharvest losses of fresh produce. V International Postharvest Symposium; 2005 June 30; Verona, Italy; 2005, pp. 2169-2176.

2. Chen J., Yuan B. (2012), Sophorolipid fruit preservative and use thereof in fruit preservation, CN 101886047 B.

3. Sharma R.R., Singh D., Singh R. (2009), Biological control of postharvest diseases of fruits and vegetables by microbial antagonists: a review. Biological Control, 50(3), pp. 205-221, doi.org/10.1016/j.biocontrol.2009.05.001.

4. Ukrainian club of agrarian business. 06.11.2018, Available at: http://ucab.ua/ua/doing_agribusiness/agrarni_rinki/ovochi.

5. Khadka R.B., Marasini M., Rawal R., Gautam D.M., Acedo A.L.Jr. (2017), Effects of variety and postharvest handling practices on microbial population at different stages of the value chain of fresh tomato (Solanum lycopersicum) in Western Terai of Nepal. BioMed Research International, Article ID 7148076, doi: 10.1155/2017/7148076.

6. Galani J.H.Y., Patel J.S., Patel N.J., Talati J.G. (2017), Storage of fruits and vegetables in refrigerator increases their phenolic acids but decreases the total phenolics, anthocyanins and vitamin $\mathrm{C}$ with subsequent loss of their antioxidant capacity. Antioxidants (Basel), 6, e59, doi: 10.3390/antiox6030059.

7. Anbudhasan P., Surendraraj A., Karkuzhali S., Sathishkumaran P. (2014), Natural antioxidants and its benefits, International Journal of Food and Nutritional Sciences, 3(6), pp. 225-232.

8. Dilarri G., da Silva V.L., Pecora H.B., Montagnolli R.N., Corso C.R., Biddia E.D. (2016), Electrolytic treatment and biosurfactants applied to the conservation of Eugenia uniflora fruit. Food Science and Technology, 36(3), doi.org/10.1590/1678-457X.00516.

9. de Oliveira M.R., Magri A., Baldo C., Camilios-Neto D., Minucelli T., Celligoi M.A.P. (2015), Review: Sophorolipids a promising biosurfactant and its applications, International Journal of Advanced Biotechnology and Research, 6(2), pp. 161-174.

10. Sinumvayo J.P., Ishimwe N. (2015), Agriculture and food applications of rhamnolipids and its production by Pseudomonas aeruginosa. Journal of Chemical Engineering and Process Technology, 6, doi.org/10.4172/2157-7048.1000223.

11. Kaur H.P., Prasad B., Kaur S. (2015), A review on application of biosurfactants produced from unconventional inexpensive wastes in food and agriculture industry, World Journal of Pharmaceutical Research, 4(8), pp. 827-842.

12. Varnier A.L., Sanchez L., Vatsa P., Boudesocque L., Garcia-Brugger A., Rabenoelina F., et al. (2009), Bacterial rhamnolipids are novel MAMPs conferring resistance to Botrytis cinerea in grapevine. Plant Cell and Environments, 32(2), pp. 178-193, doi: 10.1111/j.13653040.2008.01911.x.

13. Pirog T.P., Shevchuk T.A., Voloshina I.N., Grechirchak N.N. (2005), Use of clayditeimmobilized oiloxidizing microbial cells for purification of water from oil. Applied Biochemistry and Microbiology, 41(1), pp. 51-55, doi.org/10.1007/s10438-005-0010-z.

14. Pirog T., Sofilkanych A., Konon A., Shevchuk T., Ivanov S. (2013), Intensification of surfactants' synthesis by Rhodococcus erythropolis IMV Ac-5017, Acinetobacter calcoaceticus IMV B-7241 and Nocardia vaccinii K-8 on fried oil and glycerol containing 


\section{- Biotechnology, Microbiology-}

medium. Food and Bioproducts Processing, 91(2), pp. 149-157, doi.org/10.1016/j.fbp.2013.01.001.

15. Pirog T.P., Konon A.D., Beregovaya K.A., Shulyakova M.A. (2014), Antiadhesive properties of the surfactants of Acinetobacter calcoaceticus IMB B-7241, Rhodococcus erythropolis IMB Ac-5017 and Nocardia vaccinii IMB B-7405. Microbiology, 83(6), pp. 732-739, doi.org/10.1134/S0026261714060150.

16. Pirog T.P., Konon A.D., Sofilkanich A.P., Iutinskaia G.A. (2013), Effect of surface-active substances of Acinetobacter calcoaceticus IMV B-7241, Rhodococcus erythropolis IMV Ac5017, and Nocardia vaccinii K-8 on phytopathogenic bacteria. Applied Biochemistry and Microbiology, 49(4), pp. 360-367, doi.org/10.1134/S000368381304011X.

17. Food and Agricultural commodities production. Commodities by country/ FAOSTAT. Food and Agriculture Organization of the United Nations. Rome, 2013, Available at: http://faostat.fao.org/site/339/default.aspx.

18. Shatkovsky A.P. (2018), Tomato. Situation and opportunity for the development of open field vegetable production, Available at: http://agroua.net/plant/catalog/cg-8/c28/info/cag-408/.

19. Yan F., Xu S., Chen Y., Zheng X. (2014), Effect of rhamnolipids on Rhodotorula glutinis biocontrol of Alternaria alternata infection in cherry tomato fruit. Postharvest Biology and Technology, 97, pp. 32-35, https://doi.org/10.1016/j.postharvbio.2014.05.017.

20. Karthik R., Gobalakrishnan S., Hussain A.J., Muthezhilan R. 2013. Efficacy of Bacteriocin from Lactobacillus Sp. (AMET 1506) as biopreservative for seafood's under different storage temperature conditions, Journal of Modern Biotechnology, 2, pp. 59-65.

21. Perneel M., D’hondt L., De Maeyer K., Adiobo A., Rabaey K., Höfte M. (2008), Phenazines and biosurfactants interact in the biological control of soil-borne diseases caused by Pythium spp., Environmental Microbiology, 10(3), pp. 778-788, doi:10.1111/j.14622920.2007.01501.x.

22. Dengle-Pulate R., Joshi J., Bhagwat S., Prabhune A. (2015), Application of sophorolipids synthesized using lauryl alcohol as a germicide and fruit-vegetable wash, World Journal of Pharmaceutical Research, 3, pp. 1630-1643.

23. Mnif I., Ghribi D. (2016), Glycolipid biosurfactants: main properties and potential applications in agriculture and food industry, Journal of the Science and Food Agriculture, 96, pp. 4310-4320, doi: 10.1002/jsfa.7759.

24. Randhawa K.K.S., Rahman P.K. (2014), Rhamnolipid biosurfactants - past, present, and future scenario of global market. Frontiers in Microbiology, 5, Article number 454, doi.org/10.3389/fmicb.2014.00454.

25. Santos D.K., Rufino R.D., Luna J.M., Santos V.A., Sarubbo L.A. (2016), Biosurfactants: multifunctional biomolecules of the 21st century. International Journal of Molecular Sciences, 17(3), 401. doi: 10.3390/ijms17030401.

26. Pirog T., Shulyakova M., Sofilkanych A., Shevchuk T., Mashchenko O. (2015), Biosurfactant synthesis by Rhodococcus erythropolis IMV Ac-5017, Acinetobacter calcoaceticus IMV B7241 and Nocardia vaccinia IMV B-7405 on byproduct of biodiesel production, Food and Bioproducts Processing, 93, pp. 11-18, doi.org/10.1016/j.fbp.2013.09.003. 